\title{
LIMITATIONS AND COMPLICATIONS OF ENDOSCOPIC SURGERY FOR TREATMENT FOR SINONASAL INVERTED PAPILLOMA: A REASSESSMENT AFTER 212 CASES
}

\author{
Davide Lombardi, MD, ${ }^{1}$ Davide Tomenzoli, MD, ${ }^{1}$ Laura Buttà, MD, ${ }^{1}$ Andrea Bizzoni, MD, ${ }^{1}$ \\ Davide Farina, MD, ${ }^{2}$ Federica Sberze, MD, ${ }^{3}$ Apostolos Karligkiotis, MD, ${ }^{3}$ Paolo Castelnuovo, MD, ${ }^{3}$ \\ Piero Nicolai, MD $^{1}$
}

${ }^{1}$ Department of Otorhinolaryngology, University of Brescia, Brescia, Italy. E-mail: davinter@libero.it

${ }^{2}$ Department of Radiology, University of Brescia, Brescia, Italy

${ }^{3}$ Department of Otorhinolaryngology, University of Insubria, Varese, Italy

Accepted 26 July 2010

Published online 21 October 2010 in Wiley Online Library (wileyonlinelibrary.com). DOI: 10.1002/hed.21589

\begin{abstract}
Background. The purpose of this study was to define the optimal surgical strategy for sinonasal inverted papilloma in relation to the site of origin and tumor extent.

Methods. Retrospective analysis of patients affected by inverted papilloma treated by purely endoscopic or combined approaches at the Department of Otorhinolaryngology of the University of Brescia and Pavia-Varese from November 1991 to December 2007

Results. Two hundred twelve patients were considered eligible for this study. An exclusive endoscopic approach was performed in 198 patients (93.4\%); the remaining 14 patients (6.6\%) underwent an endoscopic approach combined with an osteoplastic frontal flap. Follow-up ranged from 24 to 192 months (mean, 53.8 months). A single recurrence was observed in 12 patients (5.7\%). Twenty complications (9.4\%) were observed.

Conclusion. Endoscopic surgery is the first choice in the treatment of inverted papilloma; only lesions with extensive involvement of frontal sinus and/or supraorbital cell may require a combined approach. A minimum follow-up of 5 years is recommended. (c) 2010 Wiley Periodicals, Inc. Head Neck 33: 1154-1161, 2011
\end{abstract}

Keywords: endoscopic sinus surgery; frontal sinus; inverted papilloma; osteoplastic frontal flap; complications

Sinonasal inverted papilloma is a benign lesion originating from the Schneiderian membrane of the mucosa that lines the nasal cavity and paranasal sinuses. ${ }^{1,2}$ First described in the $1850 \mathrm{~s},{ }^{3,4}$ the main biological features of inverted papilloma (the tendency to cause bone remodeling, propensity to recurrence, and association with squamous cell carcinoma [SCC]) have been precisely documented, although its etiology remains a matter of debate.

Correspondence to: D. Lombardi

() 2010 Wiley Periodicals, Inc.
Surgery is the mainstay of treatment for inverted papilloma; before the endoscopic era, medial maxillectomy by lateral rhinotomy or midfacial degloving was considered the gold standard to ensure complete local resection. $^{5-7}$ It is worth mentioning that these approaches, even though providing a much lower recurrence rate than simple transnasal resection not assisted by any optical aid, were also associated with a non-negligible morbidity. ${ }^{8,9}$ Since the end of the $1980 \mathrm{~s}$, due to the development of rigid endoscopic fibers and dedicated instruments together with the increase in surgical expertise, minimally invasive endoscopic approaches gradually replaced "traditional" external procedures for the excision of inverted papilloma. This evolution has clearly shown to be associated with a decreased morbidity and a similar success rate. ${ }^{1,9-11}$ At present, a purely transnasal endoscopic approach may be considered the gold standard in treatment of the vast majority of inverted papilloma, ${ }^{2,11-13}$ whereas only a minority of cases require a combined or external approach.

The present study reports the experience at 2 university centers with a uniform policy in management of inverted papilloma. Particular emphasis was placed on the definition of the optimal surgical strategy and technique in lesions arising in or involving the frontal and maxillary sinus. Preoperative diagnostic workup, follow-up strategy, and outcome will also be discussed.

\section{MATERIALS AND METHODS}

A retrospective analysis of a database dedicated to patients with inverted papilloma treated at the Department of Otorhinolaryngology at the University of Brescia and Pavia-Varese from November 1991 to December 2009 was performed.

Information on previous surgery, imaging findings, sex, age, symptoms at diagnosis, site of origin and extension of the lesion, surgical approach, association with malignancy, and re-treatment in case of 
recurrence was available. Only patients treated by a purely endoscopic or combined (endoscopic associated with external) approach and with at least 2 years of follow-up were considered eligible for inclusion in the study.

Preoperative Evaluation. Preoperative imaging by CT and/or MRI with contrast medium administration was obtained in all cases. An endoscope-guided biopsy with the patient under local anesthesia was subsequently obtained.

Surgical Technique, Exclusion Criteria for Endoscopic Resection, and Staging. All surgical procedures were performed with the patient under general anesthesia. The entity of dissection was modulated in relation to the site and extent of the lesion defined by preoperative imaging and intraoperative findings. Informed consent about the possibility of intraoperatively switching from an endoscopic to a combined approach was obtained in patients with different modalities of frontal sinus and/or supraorbital cell involvement.

Nasoethmoidal and maxillary sinus inverted papillomas were treated according to 3 different types of endoscopic procedures, which have been extensively described in a previous publication (Table 1). ${ }^{14}$ However, several details of surgical technique should be highlighted. Although en bloc resection is only occasionally feasible due to tumor bulk and/or location in poorly accessible spaces, the lesion was not removed according to a simple "piecemeal" method but with a more complex "modular" technique. This means that the goal of complete excision was achieved by disassembling the lesion in oriented blocks, starting from the endonasal portion and progressively reaching the area of attachment where the dissection was carried along the subperiosteal plane with drilling of the underlying bone. This modular resection implies that all the involved subsites with possible foci of microinvasive or invasive SCC can be perfectly located at definitive histology.

One of the most critical issues in surgery for inverted papilloma is the modality of involvement of the frontal sinus. Preoperative imaging is often not accurate enough to identify the site of origin and to clarify the extent of involvement of the frontal sinus or recess mucosa, which can be assessed only intraoperatively. When the inverted papilloma extended from the ethmoid into the frontal recess and/or sinus in a fingerlike manner, a type IIa frontal sinusotomy according to Draf' $^{15}$ classification was performed. Whenever the inverted papilloma was found to originate at the level of frontal recess, a type IIb frontal sinusotomy was used. In patients with lesions arising from the mucosa of the posterior wall of the frontal sinus, a type III frontal sinusotomy, according to Draf, ${ }^{15}$ was used. If the tumor extended to a supraorbital cell with a limited
Table 1. Summary of surgical steps of the 3 types of endoscopic procedures. ${ }^{14}$

Type of

endoscopic

procedure

Surgical steps

1 Anterior and posterior ethmoidectomy, sphenoidotomy, large middle antrostomy, partial or complete middle turbinectomy, frontal sinusotomy (type I, IIA, IIB, or III according to Draf's ${ }^{15}$ classification in relation to the extent of disease).

2

Anterior and posterior ethmoidectomy, sphenoidotomy, medial maxillectomy, partial or complete middle turbinectomy, frontal sinusotomy (type I, IIA, IIB, or III according to Draf's ${ }^{15}$ classification in relation to the extent of the disease; \pm naso-lacrimal duct section).

Anterior and posterior ethmoidectomy, sphenoidotomy, endonasal Denker operation with naso-lacrimal duct section, complete inferior and middle turbinectomy, frontal sinusotomy (type I, IIA, IIB, or III according to Draf's ${ }^{15}$ classification in relation to the extent of disease).

lateral extent, exposure was increased by laterally displacing the orbital content after coagulating and sectioning the anterior ethmoid artery before drilling the upper part of the lamina papyracea. ${ }^{16}$ Whenever extensive mucosal involvement inside a supraorbital cell extending far laterally over the orbit or a massive involvement of the frontal sinus mucosa was identified, an osteoplastic flap (OPF) using a coronal approach was required (Figure 1). Frozen sections were extensively used to assess the radicality of resection.

On the basis of radiological and surgical findings, lesions were staged according to the system of Krouse. ${ }^{17}$

Perioperative Management and Follow-Up. Patients were administered antibiotic therapy with amoxicillin-clavulanate ( $2 \mathrm{gm} /$ day for 10 days) and deflazacort (15 days, tapering the dose from 30 to 7.5 $\mathrm{mg}$ ). Irrigations with saline solution (twice daily) were recommended for at least 1 month. All patients were postoperatively followed by periodical endoscopic examinations (every 4 months during the first postoperative year, every 6 months for at least 4 years, and then once a year thereafter). Whenever sectioning of the nasolacrimal duct was performed, irrigation of the residual lacrimal pathway was performed at the end of surgery, after removal of nasal packing, and 15 days later to favor its patency. A lacrimal stent was never placed during primary procedures. Postoperative MRI evaluation was scheduled in the presence of scar tissue obscuring the visualization of the site of origin of the lesion (every 6 months for the first 2 years and then once a year for the following 3 years) 

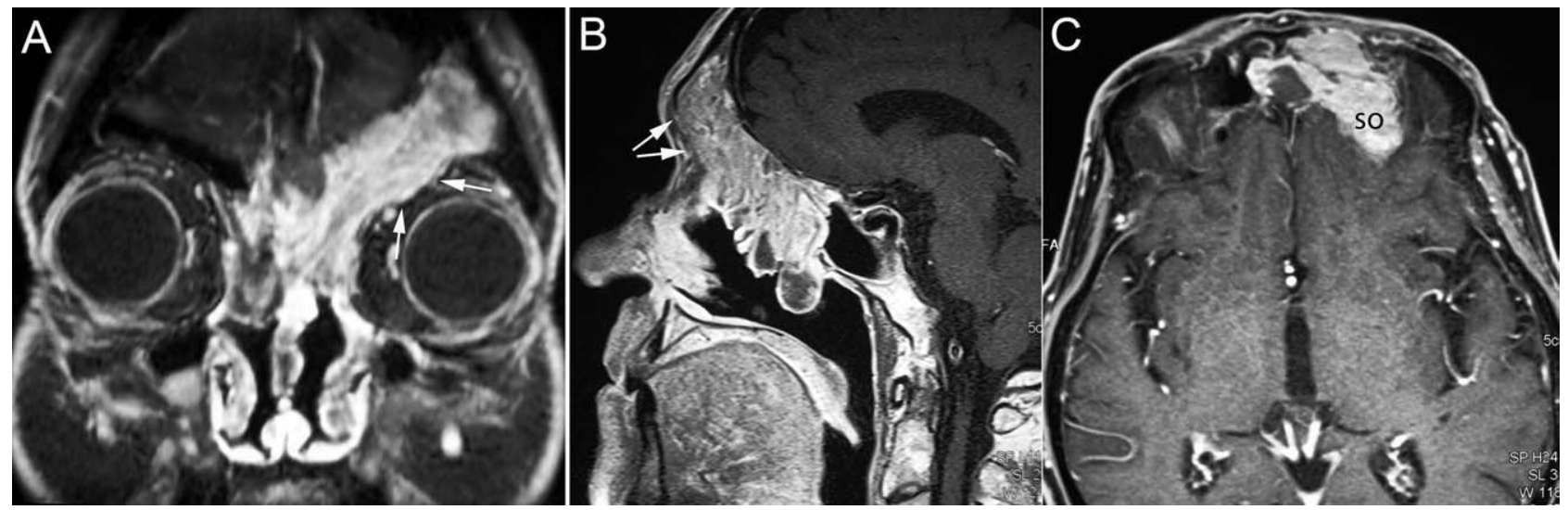

FIGURE 1. Contrast-enhanced MR images, on coronal (A), sagittal (B), and axial (C) plane in a patient who had been previously treated with a purely endoscopic approach at another institution. Left fronto-ethmoid inverted papilloma completely fills the frontal sinus and extends within a supraorbital cell (SO). Massive bone remodeling at the level of orbital roof (arrows in A) and anterior frontal sinus wall (arrows in B) is evident.

or when synchronous invasive SCC was detected at definitive histology (every 4 months for the first year, then every 6 months for the following 4 years). Whenever an inflammatory complication such as frontal sinusitis or mucocele was suspected, a CT was performed. In the presence of epiphora, a dacryocystography was obtained.

Statistical Analysis. A commercially available computer software package (SPSS for Windows, Version 10.01, 1999; SPSS, Chicago, IL) was used. Statistical analysis was performed using the Kaplan-Meier method to evaluate the risk of recurrence in relation to previous surgery, site of origin, and staging of the lesion. Univariate comparisons between groups were performed using the log-rank test. A value of $p \leq .05$ was considered statistically significant.

\section{RESULTS}

Patient Data. A total of 307 patients were treated with a purely endoscopic or combined approach; 212 patients (167 men, 45 women) fulfilled inclusion criteria and were considered eligible for the present study. The remaining 95 patients were followed up for less than 24 months and, therefore, were not included in the analysis. Mean age at surgery was 56.5 years (range, 20-86 years). Fifty-six patients (26.4\%) had been previously treated at other institutions with endoscopic $(21.4 \%)$ or external $(5 \%)$ approaches. Unilateral nasal obstruction was the presenting symptom in $89.9 \%$ of patients; other complaints included hyposmia-anosmia (18.7\%), rhinorrhea (18.2\%), headache $(17.3 \%)$, epistaxis $(11.8 \%)$, and epiphora (6\%). The diagnosis was serendipitous in 7 asymptomatic patients (3\%). An MRI was obtained in 176 cases (83\%); in 91 cases $(42.9 \%)$, a CT had been performed before the patient was sent to our institution. The remaining 36 patients (17\%) underwent a CT scan only because of claustrophobia or the presence of a pacemaker.

In 100 patients $(47.2 \%)$, the lesion originated from the nasoethmoidal complex, in 92 patients $(43.4 \%)$ from the maxillary sinus, in 11 patients (5.2\%) from the frontal, and in 9 patients $(4.2 \%)$ from the sphenoid. Bilateral involvement was present in 7 patients $(3.3 \%)$.

Surgical Technique and Staging. An exclusive endoscopic approach was used in 198 patients (93.4\%): 88 patients $(44.4 \%)$ received a type 1 resection, 62 patients $(31.3 \%)$ received a type 2 (with resection of the nasolacrimal duct in 38 cases), and 48 patients $(24.3 \%)$ received a type 3 . Fourteen patients $(6.6 \%)$ underwent an endoscopic approach combined with an OPF.

In the 11 patients with frontal sinus inverted papilloma, surgery included a transnasal endoscopic approach combined with OPF in 5 cases, a Draf III frontal sinusotomy in 4 , and a Draf IIB in 2. Moreover, in addition to the 11 cases in which the tumor originated from the mucosa of the frontal sinus, we observed 16 patients with different secondary involvement of the frontal sinus by a nasoethmoidal lesion. In this group, a Draf IIB frontal sinusotomy was performed in 7 patients, an endoscopic approach was combined with an OPF in 7 patients, and a Draf III frontal sinusotomy was performed in 2 patients.

Lesions were staged according to $\mathrm{Krouse}^{17}$ as follows: $16(7.5 \%) \mathrm{T} 1,78(36.8 \%) \mathrm{T} 2,104(49.1 \%) \mathrm{T} 3$, and $14(6.6 \%) \mathrm{T} 4$.

Histology. Definitive histology was consistent with sinonasal inverted papilloma in all cases; areas of mild dysplasia was identified in 3 patients $(1.4 \%)$ and moderate dysplasia was identified in 2 patients 
$(0.9 \%)$. Carcinoma in situ was detected in 3 patients $(1.4 \%)$ and SCC in 8 patients $(3.8 \%)$.

Adjuvant Treatment. In 5 patients with SCC, postoperative radiation therapy (60-65 Gy) on the primary site was planned.

Complications and Follow-Up. Immediate postoperative complications were observed in 8 patients (3.8\%), 7 after exclusive endoscopic approaches and 1 after following a combined approach. Six patients had a cerebrospinal fluid (CSF) leak that was intraoperatively identified and treated by endoscopic duraplasty. Two patients required revision endoscopic surgery while under general anesthesia for postoperative epistaxis.

Follow-up data were available for all patients and ranged from 24 to 192 months (mean 53.8). Delayed complications were identified in 12 patients $(5.7 \%)$. In 6 patients, a CT scan showed the presence of a mucocele ( 4 in the frontal sinus and 2 in the maxillary sinus). All underwent successful endoscopic marsupialization. In 4 cases, post-saccal lacrimal pathway obstruction was treated by endonasal dacryocystorhinostomy with lacrimal stent placement for 2 months. In the remaining 2 cases, endoscopic revision surgery was planned for frontal sinusitis that was unresponsive to medical therapy.

Two hundred patients $(94.3 \%)$ were free of disease when last seen. A single recurrence was observed in the remaining 12 cases $(5.7 \%$; Table 2); all recurrences involved the site of the primary lesion, which was the maxillary sinus in 6 of 92 cases $(6.5 \%)$, the nasoethmoidal complex in 4 of 100 cases (4\%), and the frontal sinus in the remaining 2 of 11 cases (18\%). The mean interval between surgical treatment and diagnosis of recurrence was 19 months (range, 6-70). All recurrences occurred after purely endoscopic approaches (6 after type 2 resection, 4 after type 3, and 2 after type 1). Disease in 8 of 12 patients $(66.7 \%)$ was classified as T3, in 2 patients $(16.7 \%)$ as
$\mathrm{T} 2$, in 1 patient $(8.3 \%)$ as $\mathrm{T} 4$, and in 1 patient $(8.3 \%)$ as T1. Four of the 12 patients $(33 \%)$ had been previously treated at other institutions by an endoscopic ( $n$ $=3$ ) or open approach $(n=1)$. The recurrences were treated by a purely endoscopic approach in 10 cases and by a combined approach in the remaining 2 cases (Table 2).

There was no statistically significant difference for risk of recurrence considering previous surgery ( $p$ $=.25)$, site of origin $(p=.15)$, or stage $(p=.47)$.

\section{DISCUSSION}

To the best of our knowledge, this is the largest case series presented to date in the English- language literature focusing on the role of endoscopic surgery in the management of inverted papilloma. In the last decade, several studies on surgical treatment of this lesion have confirmed the validity and efficacy of endoscopic approaches in obtaining excellent control of disease with reasonable morbidity. ${ }^{1,2,9,11,13}$ Recently, several authors have emphasized the need to modulate surgical technique on the basis of the site of attachment and extension of the inverted papilloma to minimize recurrence. ${ }^{1,18-20}$ According to Lund, ${ }^{21}$ it is worthwhile remembering that "the term 'recurrence' merely indicates residual disease in the majority of cases and is directly related to the surgical approach and the 'care' with which the inverted papilloma is removed." Therefore, a recurrence might be primarily attributed to the inability of the surgeon to achieve complete resection rather than to the intrinsic characteristics of the tumor itself. Consistently with this statement, a recent position article confirms that the outcome of treatment relates to how thoroughly the diseased mucosa is removed. ${ }^{22}$

At present, due to the evolution of imaging techniques with the possibility of acquiring multiplanar reconstructions, it has become easier to preoperatively plan surgical procedures. As reported by Sham et al, ${ }^{23} \mathrm{CT}$ evidence of focal hyperostosis or bony strut (ie, elongated bony protrusion with narrow base) has

\begin{tabular}{|c|c|c|c|c|c|c|c|}
\hline Patient & $\begin{array}{l}\text { Previous } \\
\text { surgery }\end{array}$ & $\begin{array}{l}\text { Site of } \\
\text { origin }\end{array}$ & $\begin{array}{l}\text { Krouse } \\
\text { stage }^{16}\end{array}$ & $\begin{array}{c}\text { Type of endoscopic } \\
\text { procedure }^{14}\end{array}$ & $\begin{array}{l}\text { Months to } \\
\text { recurrence }\end{array}$ & $\begin{array}{c}\text { Recurrence } \\
\text { surgical approach }\end{array}$ & $\begin{array}{c}\text { Months since } \\
\text { retreatment }\end{array}$ \\
\hline 1 & EN & $E$ & 1 & 1 & 70 & EN & 14 \\
\hline 2 & - & $\mathrm{F}$ & 3 & 3 (DRAF III) & 40 & $\mathrm{CO}$ & 35 \\
\hline 3 & - & $E$ & 3 & 2 (DRAF ॥B) & 6 & EN & 64 \\
\hline 4 & EXT & MA & 3 & 2 & 12 & EN & 58 \\
\hline 6 & EN & $E$ & 4 & 2 (DRAF ॥B) & 41 & EN & 19 \\
\hline 7 & & MP & 3 & 3 & 46 & EN & 12 \\
\hline 8 & - & MM & 3 & 3 & 19 & EN & 33 \\
\hline 9 & - & MM & 2 & 2 & 15 & EN & 31 \\
\hline 10 & - & $E$ & 2 & 1 & 8 & $\mathrm{CO}$ & 34 \\
\hline 11 & - & $M L$ & 3 & 3 & 18 & EN & 9 \\
\hline 12 & - & MP & 3 & 2 (DRAF III) & 15 & EN & 7 \\
\hline
\end{tabular}

Abbreviations: CO, combined approach; E, ethmoid; EN, endoscopic approach; EXT, external approach; $F$, frontal sinus; MA, maxillary sinus anterior wall; ML, maxillary sinus lateral wall; MM, maxillary sinus medial wall; MP, maxillary sinus posterior wall; S, sphenoid sinus. 

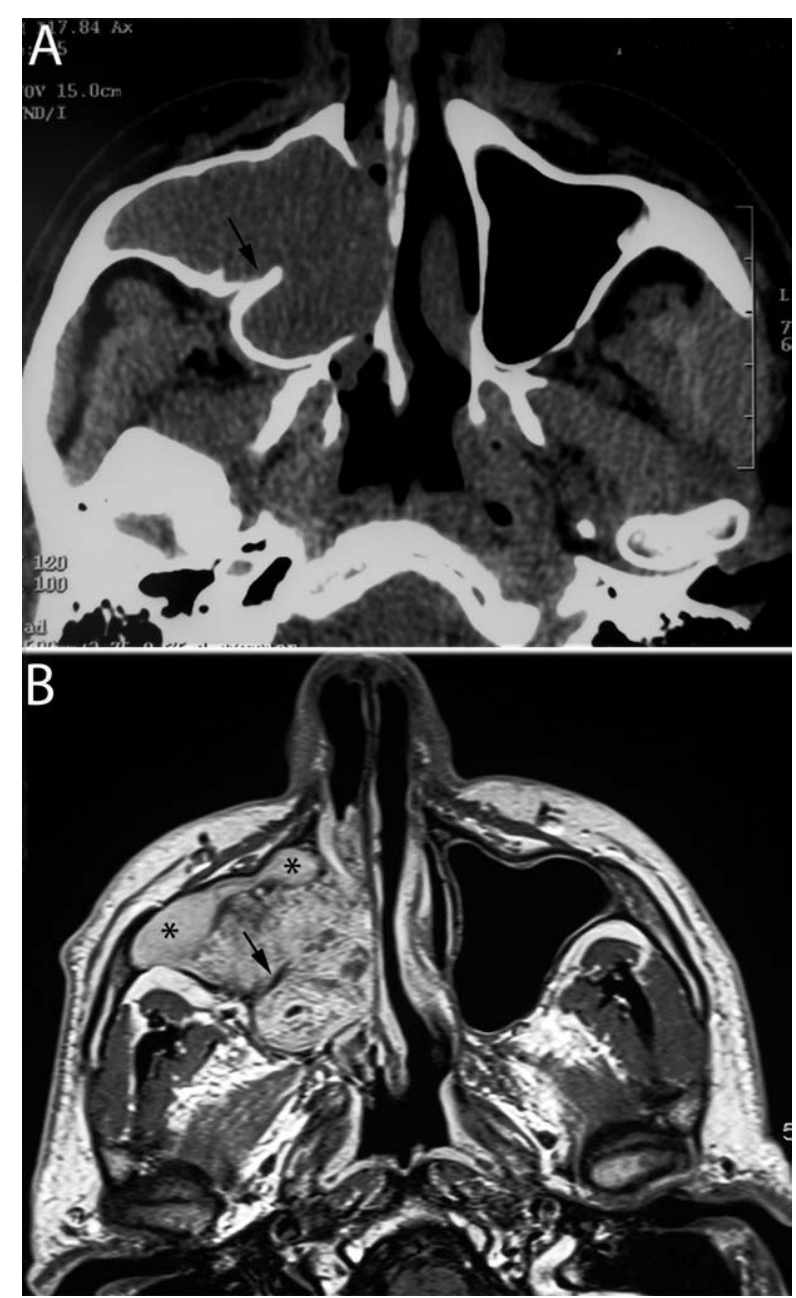

FIGURE 2. Plain CT (A) and contrast-enhanced T1-weighted spinecho MR image (B), both on an axial plane. Right maxillary sinus inverted papilloma; sinus walls are expanded and remodeled. Both techniques detected a focal strut along the posterior maxillary sinus wall, representing the attachment site of the lesion (arrows). An MRI offers clues for the characterization of the lesion (as it displays the typical cerebriform columnar pattern) and better discrimination between neoplasm and retained secretions (asterisks).

a $100 \%$ positive predictive value in identifying the attachment site of the inverted papilloma (Figure 2); osteitic changes may also be recognized at the site of origin of inverted papilloma. ${ }^{24,25}$ Nevertheless, about $20 \%$ of CT images are inaccurate in terms of defining the extension of the tumor. ${ }^{23}$ In contrast, an MRI has been shown to be more sensitive than a CT scan in differentiating inverted papilloma from intrasinusal retained secretions and identifying areas of possible malignant degeneration by describing the interface bone-lesion. ${ }^{22,26}$ Recent experiences have demonstrated that the bony alterations used to predict the site of origin of inverted papilloma can also be identified by an MRI (Figure 2). ${ }^{27}$ Moreover, detection of the "cerebriform-columnar pattern" represents a valuable indicator for differential diagnosis, with a posi- tive predictive value of $95.8 \% .^{26}$ The association of a columnar appearance with bone changes (remodeling vs erosion) allows differentiation of inverted papilloma from a malignant tumor. ${ }^{26}$ Despite the accuracy of an MRI in defining the signal characteristics of the lesion, its site of origin and relationships with critical structures, the technique is not always able to identify the degree of mucosal involvement in specific subsites, especially in those cases in which the inverted papilloma completely fills one sinus. ${ }^{16}$ If this occurs in the maxillary sinus, it is the type of endoscopic excision rather than the surgical approach that must be modulated according to intraoperative findings. In fact, in patients with a tumor arising from the nasoethmoidal complex or maxillary sinus, we were able to preoperatively predict whether a pure endoscopic resection was feasible. On the other hand, whenever massive frontal sinus involvement was detected, the need for a combined approach was always considered and discussed with the patient.

In fact, when faced with involvement of the frontal sinus, the relationship between inverted papilloma and the sinus is almost invariably assessed intraoperatively and the surgical approach is adjusted accordingly. Lesions growing marginally from the ethmoid into the frontal sinus or filling a small sinus can be effectively managed, possibly resorting to a Draf's type II or III procedure. In the presence of lesions arising at the level of frontal recess, a type IIb frontal sinusotomy permits drilling the bone underlying the site of origin of the inverted papilloma and to check the status of the frontal sinus mucosa. When the site of origin is located on the frontal sinus posterior wall, a type III frontal sinusotomy is necessary to increase the exposure and to reach the entire posterior wall with double-bent instruments.

Conversely, when the disease extensively involves the mucosa, especially in a hyperpneumatized frontal sinus or within a largely pneumatized supraorbital cell, a combined approach is needed to gain complete removal of the mucosa and to drill the underlying bone in the far lateral spaces. Because an inflamed mucosa may be very difficult to differentiate from an inverted papilloma at endoscopy, whenever the involvement of a specific subsite is suspected and/or may lead to a change in the surgical planning, intraoperative frozen sections are strongly recommended.

Other lesions that can be managed by a purely endoscopic approach are inverted papillomas with intraorbital or intracranial involvement. In recent years, owing to the evolution of endoscopic expertise in the management of $\mathrm{CSF}$ in addition to malignant tumors and lesions involving the anterior and middle cranial fossa, inverted papilloma with a limited intracranial and/or intraorbital extension can also be managed by a purely endoscopic approach. ${ }^{28}$ Even in these cases, patients scheduled for an endoscopic procedure should be informed during preoperative counseling regarding 
Table 3. Analysis of complications in series of inverted papilloma with at least 40 patients treated by a purely endoscopic (En) or combined (Co) approach since 2001

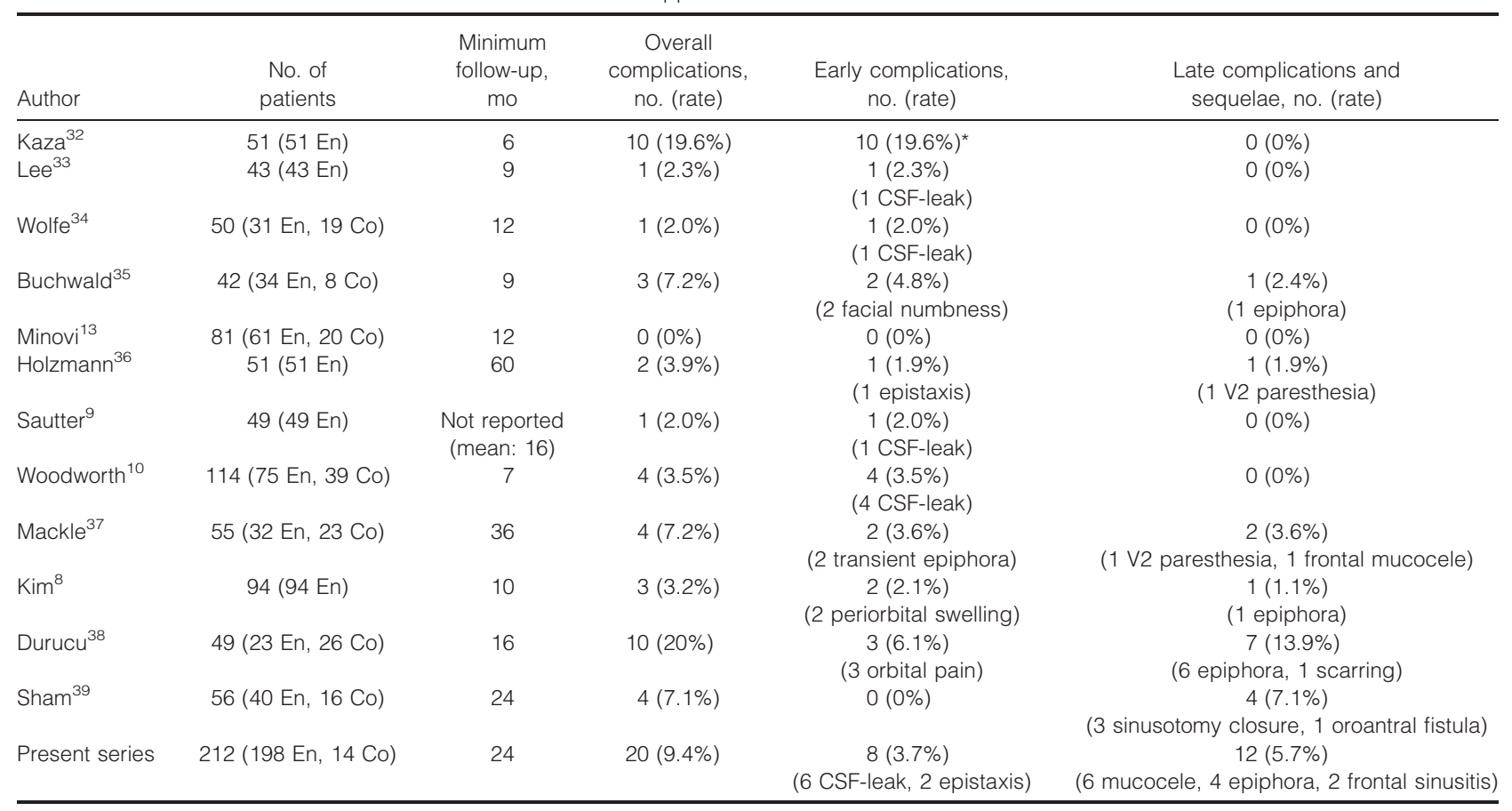

Abbreviation: CSF, cerebrospinal fluid.

*15 early complications (3 CSF, 3 temporary frontal hypoesthesia, 2 orbital fat exposure, 2 periorbital hematoma, 2 maxillary neuralgia, 2 cheek cellulitis, 1 malar rush) occurred in 10 patients.

the possibility to intraoperatively switch to a combined approach.

A further element that can impact treatment strategy is the detection, preoperatively or at definitive histology, of SCC. In our experience, only in 2 cases with preoperative biopsy consistent with an inverted papilloma, an MRI identified findings consistent with malignancy in the deep portion of the lesion. In 1 case, the patient was not considered a candidate for surgical treatment, whereas the second patient underwent craniofacial resection with orbital clearance. In no case of the present series did a preoperative biopsy reveal SCC foci associated with inverted papilloma.

In contrast, whenever macroscopic SCC is detected at definitive histology, the sites involved should be carefully evaluated to decide whether or not further treatment is needed. We planned adjuvant radiotherapy in 5 of 8 patients with nonmicroscopic, invasive SCC extending in proximity but not involving critical areas (skull base, maxillary sinus bony walls with the exception of the medial one). However, when only microscopic foci of SCC or carcinoma in situ was identified, adjuvant radiotherapy was not performed.

In addition, to correct identification of the site of origin of the lesion, its spread along the mucosa, and possible association with SCC, all factors which can modulate the choice of the surgical approach, another key point to obtaining radical excision is the use of appropriate dissection technique. Once the site of origin has been identified, in fact, this should be carried along the subperiosteal plane with subsequent drilling by a diamond burr of the underlying bone. Only by following these principles of management can the risk of recurrence be minimized.

The recurrence rate of $5.7 \%$ observed in our series of 212 patients favorably compares with data for both endoscopic and external approaches (4\% to $22 \%)^{1,8-}$ $10,13,18$ All the recurrences in the present series were observed at the same site of the primary lesion and after purely endoscopic removal. Although most recurrences $(66.6 \%)$ were diagnosed within 24 months, at least 5 years of follow-up are recommended. The followup strategy is based upon periodic endoscopic evaluations; integration with an MRI should be scheduled only when the site of origin of the inverted papilloma is not visible at endoscopy, a recurrence is detected, or SCC is identified at definitive histology.

Even though inverted papillomas of the frontal sinus were associated with a higher rate of recurrence $(18 \%)$ compared to those of the maxillary sinus and nasoethmoidal complex $(6.5 \%$ and $4 \%$, respectively), no statistically significant difference was observed, possibly due to the limited number of cases. No recurrence occurring primarily in the frontal sinus was observed when a combined technique was used. Although this observation reinforces the importance of accurate selection of the surgical approach, it should not lead one to conclude that $\mathrm{OPF}$ is the first choice in all inverted papillomas 
involving the frontal sinus. In fact, OPF is indicated only in selected cases with extensive frontal sinus and/or supraorbital cell involvement. This approach is indeed characterized by morbidity that should not be underestimated, including unintentional fracture or incorrect placement of frontal sinus anterior wall, adverse aesthetic consequences due to skin incision and/or changes of frontal contour (depression, embossment), frontal anesthesia and supraorbital nerve neuralgia. ${ }^{29-31}$

Overall, 20 complications $(9.4 \%)$ were observed, and were classified as early (8 cases, $3.7 \%$; ie, occurring intraoperatively and in the immediate postoperative time), and late (12 cases, 5.7\%). According to a review of the literature (Table 3 ), the overall complication rate ranges between $0 \%$ and $20 \%$ (mean, $6.5 \%$ ), with early and late complication rates ranging between $0 \%$ and $19.6 \%$ (mean, $4.0 \%$ ) and $0 \%$ and $13.9 \%$ (mean, $2.5 \%$ ), respectively. It is quite evident that the somewhat higher complication rate observed in the present series is mainly due to the late complications. Some speculations may be offered to explain this finding. First of all, the length of our follow-up, which reaches 192 months with a mean of 53.8 months, can justify late onset complications. Another element that needs to be considered is the relatively high number of CSF leaks (6 cases) compared to data in the literature. If we consider that our surgical technique includes subperiosteal dissection of the lesion and drilling of the underlying bone, both of which are key elements in achieving a low recurrence rate, it is intuitive that these steps also expose a patient with an inverted papilloma originating from or involving the anterior skull base to a major risk of dural lesion.

\section{CONCLUSIONS}

Advances in imaging techniques, increased experience with endoscopic surgery, and careful analysis of the pattern of recurrence have helped to refine modern surgical management of inverted papilloma. Endoscopic surgery is now the first choice in the treatment of inverted papilloma, owing to the multi-angle magnified view of the surgical field, the availability of powered instrumentation and the attachment-oriented surgical strategy, with decreased morbidity and hospitalization time compared to external approaches. In our opinion, in centers with longstanding experience in endoscopic sinus surgery the vast majority of cases can be managed endoscopically; only in patients with a tumor showing extensive involvement of the frontal sinus may a switch to a combined approach be required. The analysis of recurrences demonstrates that, although the highest risk is in the first 2 postoperative years, it is advisable to extend follow-up for at least 5 years.

\section{REFERENCES}

1. Lawson W, Patel ZM. The evolution of management for inverted papilloma: an analysis of 200 cases. Otolaryngol Head Neck Surg 2009;140:330-335.
2. Reh DD, Lane AP. The role of endoscopic sinus surgery in the management of sinonasal inverted papilloma. Curr Opin Otolaryngol Head Neck Surg 2009;17:6-10.

3. Ward N. A mirror of the practice of medicine and surgery in the hospitals of London. Lancet 1854;2:480-482.

4. Billroth T. Ueber dem Bau der Schleimpolyp (about the construction of a mucus polyp) G. Reimer $1855 ; 11$.

5. Bielamowicz S, Calcaterra TC, Watson D. Inverting papilloma of the head and neck: the UCLA update. Otolaryngol Head Neck Surg 1993;109:71-76.

6. Myers EN, Fernau JL, Johnson JT, Tabet JC, Barnes EL. Management of inverted papilloma. Laryngoscope 1990;100:481-490.

7. Myers EN, Schramm VL Jr, Barnes EL Jr. Management of inverted papilloma of the nose and paranasal sinuses. Laryngoscope 1981;91:2071-2084.

8. Kim YM, Kim HS, Park JY, Koo BS, Park YH, Rha KS. External vs endoscopic approach for inverted papilloma of the sino-nasal cavities: a retrospective study of 136 cases. Acta Otolaryngol 2008;128:909-914.

9. Sautter NB, Cannady SB, Citardi MJ, Roh HJ, Batra PS. Comparison of open versus endoscopic resection of inverted papilloma. Am J Rhinol 2007;21:320-323.

10. Woodworth BA, Bhargave GA, Palmer JN, et al. Clinical outcomes of endoscopic and endoscopic-assisted resection of inverted papillomas: a 15-year experience. Am J Rhinol 2007;21:591-600.

11. Busquets JM, Hwang PH. Endoscopic resection of sinonasal inverted papilloma: a meta-analysis. Otolaryngol Head Neck Surg 2006;134:476-482.

12. Karkos PD, Fyrmpas G, Carrie SC, Swift AC. Endoscopic versus open surgical interventions for inverted nasal papilloma: a systematic review. Clin Otolaryngol 2006;31:499-503.

13. Minovi A, Kollert M, Draf W, Bockmühl U. Inverted papilloma: feasibility of endonasal surgery and long-term results of 87 cases. Rhinology 2006;44:205-210.

14. Tomenzoli D, Castelnuovo P, Pagella F, et al. Different endoscopic surgical strategies in the management of inverted papilloma of the sinonasal tract: experience with 47 patients. Laryngoscope 2004;114:193-200.

15. Draf W. Endonasal micro-endoscopic frontal sinus surgery: the Fulda concept. Op Tech Otolaryngol Head Neck Surg 1991;2: 234-240.

16. Nicolai P, Tomenzoli D, Lombardi D, Maroldi R. Different endoscopic options in the treatment of inverted papilloma. Op Tech Otolaryngol Head Neck Surg 2006;17:80-86.

17. Krouse JH. Development of a staging system for inverted papilloma. Laryngoscope 2000;110:965-968.

18. Lee TJ, Huang CC, Chen YW, Chang KP, Fu CH, Chang PH. Medially originated inverted papilloma. Otolaryngol Head Neck Surg 2009;140:324-329.

19. Yoon BN, Batra PS, Citardi MJ, Roh HJ. Frontal sinus inverted papilloma: surgical strategy based on the site of attachment. Am J Rhinol Allergy 2009;23:337-341.

20. Landsberg R, Cavel O, Segev Y, Khafif A, Fliss DM. Attachment-oriented endoscopic surgical strategy for sinonasal inverted papilloma. Am J Rhinol 2008;22:629-634.

21. Lund VJ. Optimum management of inverted papilloma. J Laryngol Otol 2000;114:194-197.

22. Lund V, Stammberger H, Nicolai P, et al. European position paper on endoscopic management of tumours of the nose, paranasal sinuses and skull base. Rhinology Suppl 2010;22:1-143.

23. Sham CL, King AD, van Hasselt A, Tong MC. The roles and limitations of computed tomography in the preoperative assessment of sinonasal inverted papillomas. Am J Rhinol 2008;22:144-150.

24. Bhalla RK, Wright ED. Predicting the site of attachment of sinonasal inverted papilloma. Rhinology 2009;47:345-348.

25. Yousuf K, Wright ED. Site of attachment of inverted papilloma predicted by CT findings of osteitis. Am J Rhinol 2007;21:32-36.

26. Maroldi R, Farina D, Palvarini L, Lombardi D, Tomenzoli D, Nicolai P. Magnetic resonance imaging findings of inverted papilloma: differential diagnosis with malignant sinonasal tumors. Am J Rhinol 2004;18:305-310.

27. Nicolai P, Castelnuovo P. Benign tumors of the sinonasal tract. In: Flint P, Haughey B, Lund V, Niparko J, Richardson M, Robinson K, Regan Thomas J, editors. Cummings Otolaryngology Head and Neck Surgery (5th edition). Elsevier; 2010. pp 717727.

28. Bignami M, Pistochini A, Meloni F, Delahaye E, Castelnuovo P. A rare case of oncocytic Schneiderian papilloma with intradural and intraorbital extension with notes of operative techniques. Rhinology 2009;47:316-319. 
29. Weber R, Draf W, Keerl R, et al. Osteoplastic frontal flap surgery with fat obliteration: technique and long-term results using magnetic resonance imaging in 82 operations. Laryngoscope 2000; 110:1037-1044.

30. Lawson W, Reino AJ. Management of embossment following the frontal osteoplastic operation. Laryngoscope 1996;106:1259_ 1265.

31. Catalano PJ, Lawson W, Som P, Biller HF. Radiographic evaluation and diagnosis of the failed frontal osteoplastic flap with fat obliteration. Otolaryngol Head Neck Surg 1991;104:225-234.

32. Kaza S, Capasso R, Casiano RR. Endoscopic resection of inverted papilloma: University of Miami experience. Am J Rhinol 2003;17:185-190.

33. Lee TJ, Huang SF, Huang CC. Tailored endoscopic surgery for the treatment of sinonasal inverted papilloma. Head Neck 2004;26:145-153.

34. Wolfe SG, Schlosser RJ, Bolger WE, Lanza DC, Kennedy DW. Endoscopic and endoscope-assisted resections of inverted sino- nasal papillomas. Otolaryngol Head Neck Surg 2004;131:174179.

35. Von Buchwald C, Larsen AS. Endoscopic surgery of inverted papillomas under image-guidance-a prospective study of 42 consecutive cases at a Danish university clinic. Otolaryngol Head Neck Surg 2005;132:602-607.

36. Holzmann D, Hegyi I, Rajani GP, Harder-Ruckstuhl M. Management of benign inverted papilloma avoiding external approaches. J Laryngol Otol 2007;121:548-554.

37. Mackle T, Chambon G, Garrel R, Meieff M, Crampette L. Endoscopic treatment of sinonasal papilloma: a 12 year review. Acta Otolaryngol 2008;128:670-674.

38. Durucu C, Baglam T, Karatas E, Mumbuc S, Kanlikama M. Surgical treatment of inverted papilloma. J Craniofac Surg 2009;20:1985-1988.

39. Sham CL, Woo JK, van Hasselt CA, Tong MC. Treatment results of sinonasal inverted papilloma: an 18-year study. Am J Rhinol Allergy 2009;23:203-211. 